\title{
Fear of Liftoff: Uncertainty, Rules, and Discretion in Monetary Policy Normalization
}

\author{
Athanasios Orphanides
}

\begin{abstract}
As the author describes it, the Federal Reserve's muddled mandate to attain simultaneously the incompatible goals of maximum employment and price stability invites short-term-oriented discretionary policymaking inconsistent with the systematic approach needed for monetary policy to contribute best to the economy over time. Fear of liftoff-the reluctance to start the process of policy normalization after the end of a recession-serves as an example. Drawing on public choice and cognitive psychology perspectives, the author discusses causes of this problem: The Federal Reserve could adopt a framework that relies on a simple policy rule subject to periodic reviews and adaptation. Replacing meetingby-meeting discretion with a simple policy rule would eschew discretion in favor of systematic policy. Periodic review of the rule would allow the Federal Reserve the flexibility to account for and occasionally adapt to the evolving understanding of the economy. Congressional legislation could guide the Federal Reserve in this direction. However, the Federal Reserve may be best placed to select the simple rule and could embrace this improvement on its own, within its current mandate, with the publication of a simple rule along the lines of its statement of longer-run goals. (JEL E32, E52, E58, E61)
\end{abstract}

Federal Reserve Bank of St. Louis Review, Third Quarter 2015, 97(3), pp. 173-96.

$\mathbf{T}$

he Federal Reserve has faced unprecedented challenges since the onset of the most recent recession in December 2007. The downturn was exacerbated by the most severe financial crisis since the Great Depression and prompted an unprecedented policy response. By the time the recession ended in June 2009, it had become the longest in post-World War II history. Monetary policy has remained unprecedented since then. Massive monetary policy accommodation in the form of quantitative easing (QE) was engineered by the Federal Reserve long after the end of the recession; and, even today-six years after the end of the recession-the Federal Reserve has yet to begin the process of normalization. Does the observed delay in normalizing policy suggest a break with the past? Does it lend

Athanasios Orphanides is a professor of the practice of global economics and management at the Sloan School of Management at the Massachusetts Institute of Technology. He is a former senior advisor of the Federal Reserve Board, a former governor of the Central Bank of Cyprus, and a former member of the Governing Council of the European Central Bank. This article is based on the author's Homer Jones Memorial Lecture at the Federal Reserve Bank of St. Louis on June 3, 2015. The author thanks Jeff Fuhrer, Marvin Goodfriend, Gregory Hess, Kevin Kliesen, David Lindsey, Ed Nelson, Peter Ireland, Stephen Williamson, Paul Tucker, and participants at the lecture as well as at the 2015 meeting of the Society for Computational Economics for helpful discussions and comments.

(C) 2015, Federal Reserve Bank of St. Louis. The views expressed in this article are those of the author(s) and do not necessarily reflect the views of the Federal Reserve System, the Board of Governors, or the regional Federal Reserve Banks. Articles may be reprinted, reproduced, published, distributed, displayed, and transmitted in their entirety if copyright notice, author name(s), and full citation are included. Abstracts, synopses, and other derivative works may be made only with prior written permission of the Federal Reserve Bank of St. Louis. 


\section{Orphanides}

support to broader concerns about the monetary policy strategy of the Federal Reserve and calls for changing the legal framework governing the institution? ${ }^{1}$ What are the risks associated with fear of liftoff?

Using the current environment as a springboard, the goal of this article is to put the Federal Reserve's policy problem in a historical perspective and assess institutional safeguards that can ensure that monetary policy contributes in the best possible manner to economic prosperity in our democratic society. Themes discussed along the way would be recognized as hardy perennials: How systematic, transparent, and predictable should monetary policy be? What are the practical challenges faced in an uncertain and constantly evolving macroeconomic landscape? How much discretion should be encouraged or tolerated to deliver reasonably good outcomes in practice? ${ }^{2}$

In the United States and elsewhere, the central bank has been granted considerable independence to encourage systematic monetary policy and protect the policy process from politics and other factors that invite populist "short-termist" behavior-behavior that favors immediate gratification at a long-term loss to society. But central bank independence may be insufficient to achieve good results when policy is set in a discretionary fashion, especially when the central bank is overburdened with numerous and potentially incompatible objectives.

The historical record of Federal Reserve policymaking is decidedly mixed. In its first hundred years, the Federal Reserve experienced ups and downs, with periods of good, bad, and terrible policy. For a number of years before the latest recession, policy compared well with the past. Policy since the end of the latest recession, however, has raised concerns. Policy liftoff has been debated, on and off, for at least five years. While the depth of the recession justified a delay in the early stages of the recovery, the Federal Reserve's continuing reluctance to start the policy normalization process suggests a deviation from the earlier norm. Placing recent policy decisions in a historical context and evaluating the causes for this apparent deviation provides guidance on how the institutional environment governing monetary policy in the United States can be improved.

\section{FOUR RECESSIONS}

A comparison of the unemployment, inflation, and interest rates over the past four business cycles is a useful starting point to put the most recent recession in historical perspective. Focusing on the three recessions before the most recent provides a useful benchmark as this period spans what has become known as the Great Moderation, a period generally associated with greater success in the formulation of monetary policy than the period preceding it. ${ }^{3}$

Figure 1 shows the evolution of the unemployment rate in the United States over the past four business cycles. ${ }^{4}$ Vertical lines denote peaks and troughs of recessions as determined by the National Bureau of Economic Research (NBER) Business Cycle Dating Committee. A distinguishing characteristic of recessions is that the unemployment rate rises sharply during the downturn, peaks at or soon after the trough, and subsequently declines for a number of years. The latest recession was associated with a very large increase in the unemployment rate and has been called the Great Recession. Note, however, that the unemployment rate did not 


\section{Figure 1}

\section{Four Recessions: Unemployment}

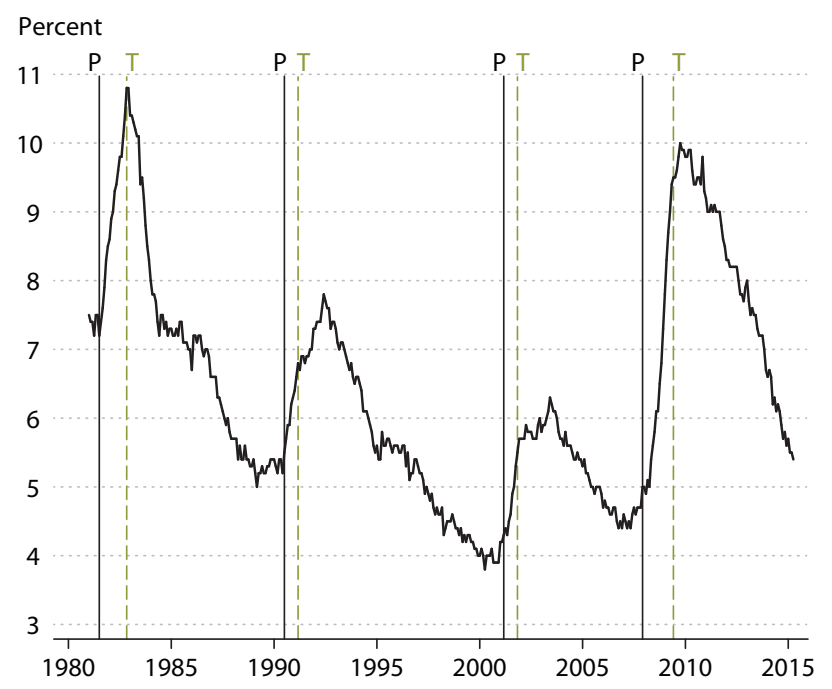

NOTE: The vertical lines denote business cycle peaks $(P)$ and troughs $(T)$.

SOURCE: FRED ${ }^{\circledR}$, Federal Reserve Economic Data, Federal Reserve Bank of St. Louis; and NBER for business cycle dates.

\section{Figure 2}

\section{Four Recessions: Inflation}

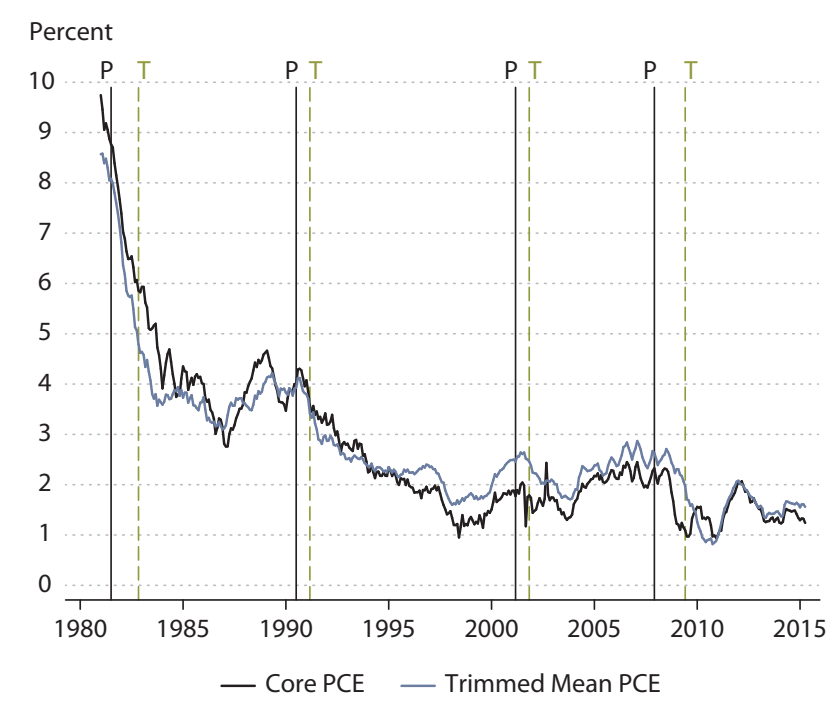

NOTE: The vertical lines denote business cycle peaks $(P)$ and troughs $(T)$. PCE, personal consumption expenditures. SOURCE: FRED ${ }^{\circledR}$, Federal Reserve Economic Data, Federal Reserve Bank of St. Louis for core PCE; and Federal Reserve Bank of Dallas for trimmed mean PCE. 


\section{Orphanides}

\section{Figure 3}

\section{Four Recessions: Real Interest Rate}

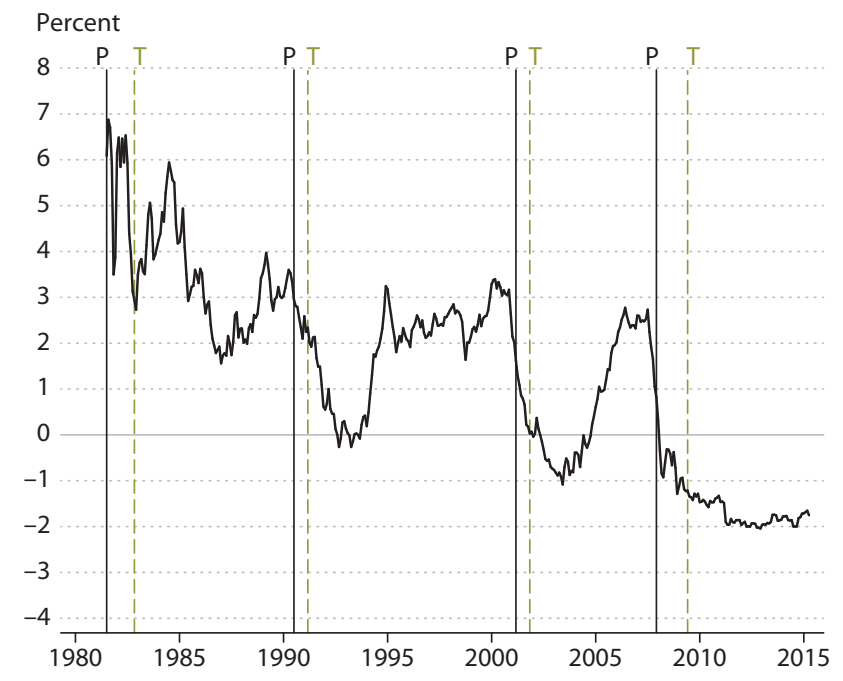

NOTE: The real interest rate reflects the difference between the 12-month T-bill rate and the year-ahead inflation expectations rate. The vertical lines denote business cycle peaks $(\mathrm{P})$ and troughs $(\mathrm{T})$.

SOURCE: FRED ${ }^{\oplus}$, Federal Reserve Economic Data, Federal Reserve Bank of St. Louis for T-bill data; Federal Reserve Bank of Philadelphia for inflation expectations; and author's calculations.

\section{Figure 4}

\section{Additional Policy Accommodation through QE}

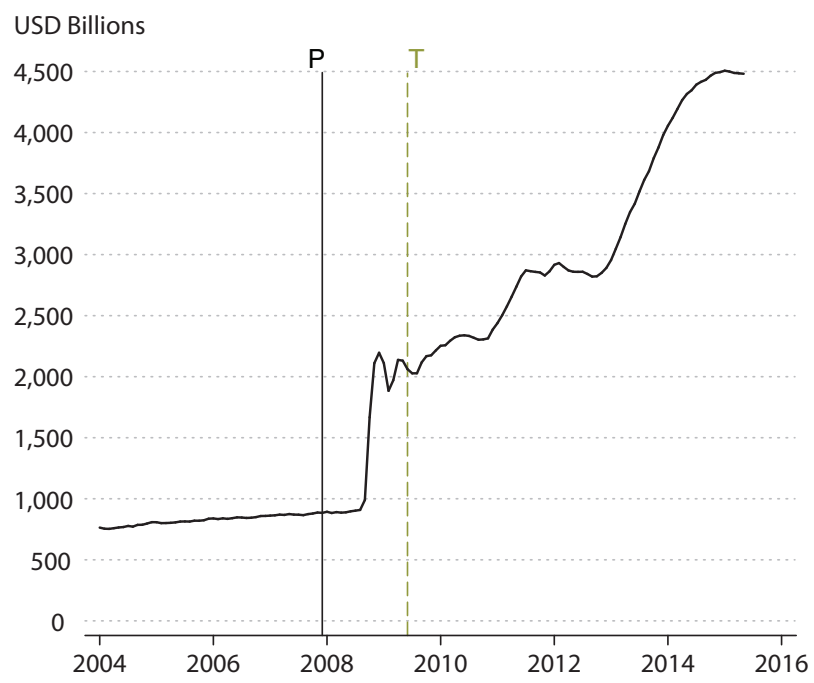

NOTE: The figure shows the size of the Federal Reserve balance sheet. The vertical lines denote business cycle peaks $(P)$ and troughs $(T)$.

SOURCE: FRED ${ }^{\oplus}$, Federal Reserve Economic Data, Federal Reserve Bank of St. Louis. 
reach the peak it had reached during 1982. Arguably, the 1981-82 recession was more painful than the most recent episode even though it did not earn the moniker the Great Recession.

Figure 2 shows the corresponding history of inflation. The figure plots core and trimmed mean inflation measures to avoid the distraction of fluctuations driven by highly volatile components. As the figure shows, overall, inflation was relatively stable over the past three business cycles, in contrast to the experience during the 1981-82 recession. Indeed, the high inflation episode that ended with the 1981-82 recession is one reason the high unemployment rate during 1982 is not judged as negatively as the high unemployment rate in the most recent recession. The high unemployment rate tolerated during the 1981-82 recession could be viewed as the price the country had to pay to correct for earlier excesses that gave rise to the malaise of high inflation.

The evolution of real interest rates highlights the response of monetary policy across these four recessions. One proxy, shown in Figure 3, can be constructed as the difference between the 12-month Treasury bill rate and the year-ahead inflation expectations reflected in the Survey of Professional Forecasters (SPF). The current episode had the most massive policy accommodation that can be seen in this sample. For the past five years, the Federal Reserve has engineered a very negative short-term real interest rate-much more negative than during the previous two recessions, when inflation was similar to the current episode. A much higher real interest rate was tolerated during and after the 1981-82 recession, but that episode is not comparable, as the tight policy was needed to tame inflation.

In addition to the massive policy accommodation engineered during the latest recession as seen in the real interest rate, another exceptional feature is the large expansion of the Federal Reserve balance sheet (Figure 4). With policy rates close to zero-as they have been since late 2008 - an expansion of the balance sheet provides additional monetary policy accommodation, beyond what is associated with the reduction in the short-term real interest rate. ${ }^{5}$ What is remarkable in this episode is how much additional policy accommodation was provided long after the recession ended in June 2009. As the figure shows, the QE policy in 2011 (QE2) and even more so the open-ended QE policy that started in September 2012 (QE3) and ended only in October 2014, led to a doubling of the size of the Federal Reserve balance sheet compared with its level at the end of the recession.

\section{EXTRAORDINARY POLICY ACCOMMODATION AFTER THE LATEST RECESSION}

The policy easing associated with the latest recession, as compared with past experience, raises a number of questions. Two pertinent questions are why the Federal Reserve has engineered this extraordinary degree of policy accommodation so long after the end of the recession and why the Federal Reserve has not yet taken any steps toward beginning the process of normalizing policy.

One answer can be found in the rationale that apparently served to justify the policy. Characteristic is the hint provided in a speech by Ben Bernanke at the last Jackson Hole Symposium he attended as Federal Reserve Chairman. The speech was delivered on August 31, 


\section{Orphanides}

2012, and effectively telegraphed the QE3 policy that started two weeks later. Bernanke (2012) argued that (i) the recovery from the recession until then was weaker than had been anticipated and (ii) the unemployment rate remained higher than hoped. Suggesting that more improvement could be sought, he remarked:

[F]ollowing every previous U.S. recession since World War II, the unemployment rate has returned close to its pre-recession level, and, although the recent recession was unusually deep, I see little evidence of substantial structural change in recent years.

If one were to interpret the Chairman's observation as a guide for policy, which is suggestive, one might have thought that the Federal Reserve had determined that even though three years had already passed since the end of the recession-and despite the unprecedented monetary policy accommodation already in place-additional easing was desirable to push the unemployment rate lower and about in line with the low level in the pre-recession mid-2000s. What Chairman Bernanke did not clarify at the time, however, was whether pushing so hard to lower the unemployment rate after recessions had always proven to be good policy for the Federal Reserve. Experience suggests otherwise. Recalling the post-World War II experience of the United States, we know that a strategy of easing policy aiming at pushing the unemployment rate down has not always been a happy experience for the Federal Reserve. During the 1960s and 1970s, activist policies with excessive emphasis on reducing the unemployment rate after recessions not only did not deliver good macroeconomic outcomes but, on the contrary, added to instability in the economy. ${ }^{6}$

As already mentioned, the unemployment rate tends to rise quickly during recessions. It also tends to be a lagging indicator and may increase somewhat further after the end of a recession. In the most recent episode, for example, the recession ended in June 2009 while the unemployment rate peaked at 10 percent in October 2009. After a recession ends, as the economy improves and with the monetary accommodation engineered in response to the recession still in place, the unemployment rate tends to gradually decline over a period of years. In the case of the latest recession, by August 2012 the unemployment rate had already declined by 2 percentage points from its peak of 8 percent and was expected to decline further. This is the context in which the decision to embark on QE3 in September 2012 was made. The zeal with which the Federal Reserve pursued monetary policy accommodation to reduce unemployment following the Great Recession appeared to resemble the mentality of monetary policy before rather than during the Great Moderation era.

\section{THE CASE OF THE MISSING LIFTOFF}

What is the pattern of monetary policy after recessions end? When does the policy-easing cycle end and the process of normalization begin? As shown in Figure 5, which plots the federal funds rate, a pattern of continued policy easing for some time after the end of a recession is not uncommon. In the current episode, with the federal funds rate close to zero by the end of the recession, the QE policy described earlier served this role. Subsequently, as the economy improves, the process of unwinding this process commences. This is when policy liftoff is observed. 


\section{Figure 5}

\section{Federal Funds Rate and Liftoff}

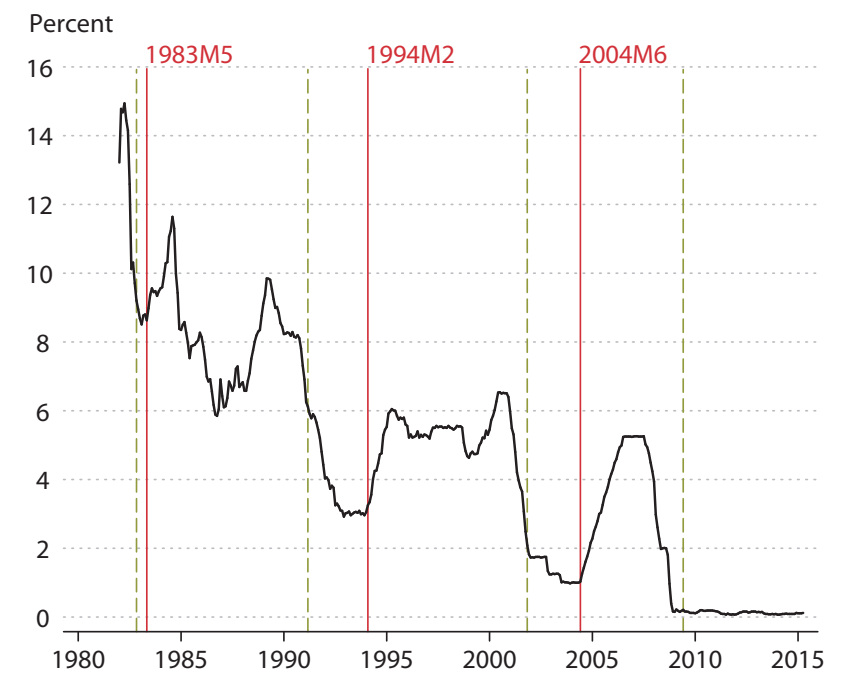

NOTE: The green vertical lines denote business cycle troughs. The red vertical lines denote the month of liftoff following business cycle troughs.

SOURCE: FRED ${ }^{\circledR}$, Federal Reserve Economic Data, Federal Reserve Bank of St. Louis.

\section{Table 1}

Policy Liftoff After the End of Four Recessions

\begin{tabular}{ccccc}
\multicolumn{2}{c}{ Recession dates } & & \multicolumn{2}{c}{ Policy liftoff } \\
\cline { 5 - 5 } Peak & Trough & & Liftoff month & Months after trough \\
\hline July 1981 & November 1982 & & May 1983 & 7 \\
July 1990 & March 1991 & & February 1994 & 35 \\
March 2001 & November 2001 & & June 2004 & 32 \\
December 2007 & June 2009 & $?$ & $72+$ \\
\hline
\end{tabular}

Liftoff occurred on May 1983, February 1994, and June 2004 for the first three recessions (shown by the red lines in Figure 5); the liftoff dates ranged from within a year to within three years from the end of a recession. (The recession and liftoff dates are summarized in Table 1.) By contrast, in the latest episode, six years after the end of the recession liftoff has yet to be observed. And this is despite the massive policy accommodation- much greater than in the previous three business cycles - that will need to be unwound to normalize policy.

What is the cause of this delay? One consideration is that the date of liftoff should depend on the state of the economy, in particular the assessment of how far the recovery has progressed from the end of the recession. As suggested in the remark by Ben Bernanke that was quoted 


\section{Figure 6}

\section{Unemployment and Liftoff}

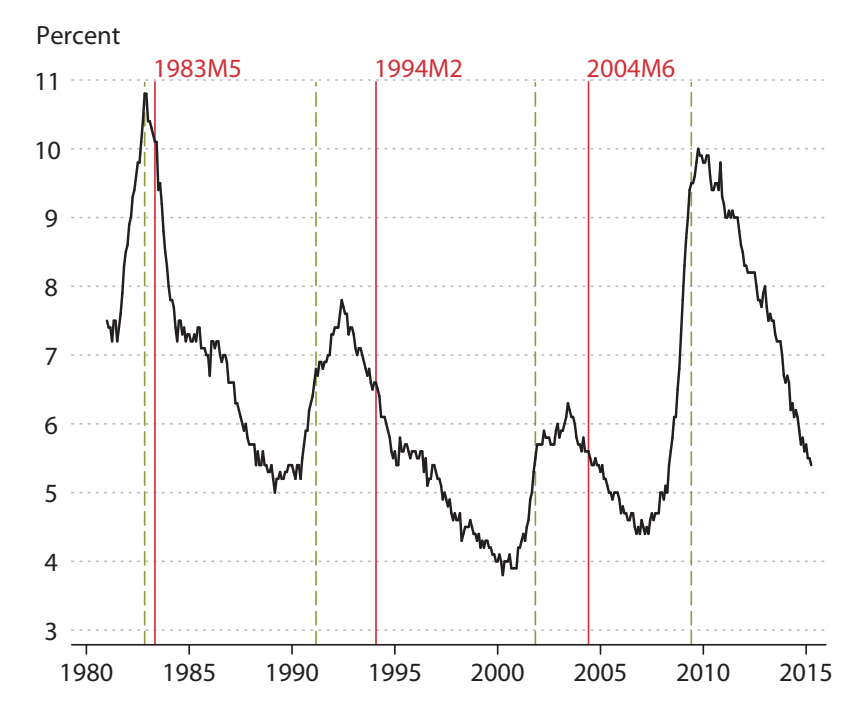

NOTE: The green vertical lines denote business cycle troughs. The red vertical lines denote the month of liftoff following business cycle troughs.

SOURCE: FRED ${ }^{\circledR}$, Federal Reserve Economic Data, Federal Reserve Bank of St. Louis.

earlier, one indicator is how much progress has been made in restoring the unemployment rate to a low level. To the extent that progress has been slower in the latest episode relative to the earlier recessions, some of the delay may be explained and is not inconsistent with past experience. But there are limits to this argument.

Liftoff is not the end of the phase of improvement in the economy. When monetary policy is appropriately conducted, liftoff does not mark the end of the expansion phase of the business cycle. Figure 6 illustrates this point by reproducing the unemployment rate and adding vertical lines indicating recession troughs and the subsequent policy liftoff dates. Judging from past experience in a period when monetary policy is generally considered to have been successful, the economy continues to improve long after liftoff occurs.

What then might serve as a benchmark for when liftoff is overdue? Perhaps the notion of the natural rate of unemployment could serve this role-that is, the rate of unemployment corresponding to "full employment" in the sense that it is compatible with price stability over the long run. Indeed, numerous policymakers have referred to estimates of full employment and the natural rate of unemployment as informing their thinking about policy. ${ }^{7}$ One complication is that the natural rate of unemployment is not observed and estimates are highly uncertain and subject to revision, a reason not all policymakers consider the concept particularly useful for policy deliberations. Still, it is instructive to examine the historical experience of liftoff in relation to the progress made by the economy following a recession relative to reasonable estimates of the natural rate of unemployment. 


\section{Figure 7}

\section{Full Employment Estimates and Liftoff}

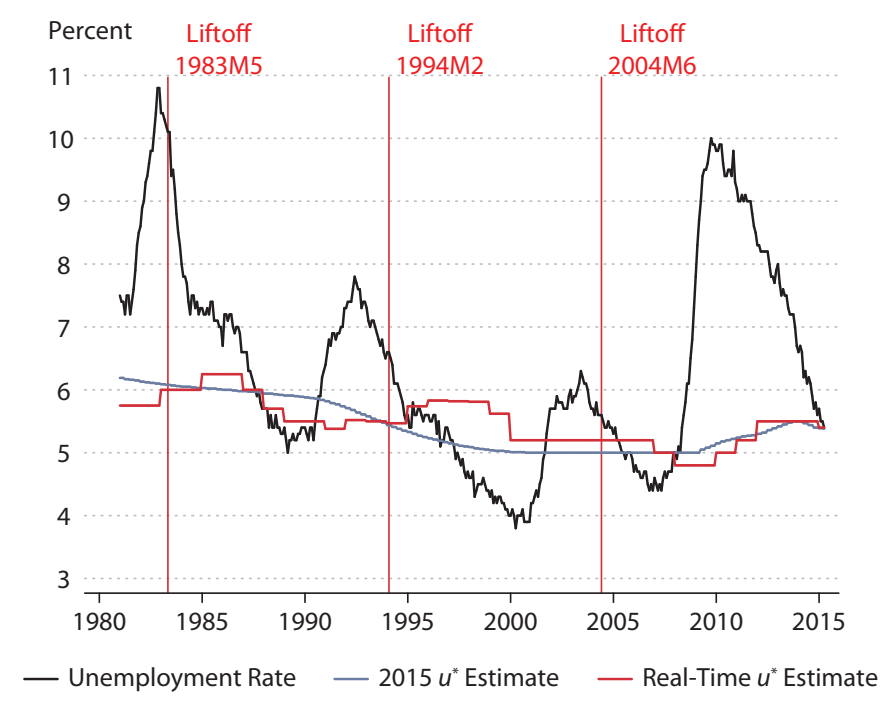

NOTE: Estimates of the natural rate of unemployment $\left(u^{*}\right)$ as published by the CBO. The 2015 estimates are from January 2015. Real-time estimates show in each year the CBO estimate published during that year.

SOURCE: FRED ${ }^{\circledR}$, Federal Reserve Economic Data, Federal Reserve Bank of St. Louis for the unemployment rate; $C B O$ for $u^{*}$.

\section{Table 2}

\section{Unemployment Rate and Policy Liftoff}

\begin{tabular}{cccccc}
\multicolumn{2}{c}{ Dates } & & \multicolumn{3}{c}{ Unemployment rate (\%) } \\
\cline { 1 - 2 } \cline { 5 - 6 } Recession trough & Liftoff month & & Actual & Natural (real-time) & Gap \\
\hline November 1982 & May 1983 & & 10.1 & 6.0 & 4.1 \\
March 1991 & February 1994 & & 6.4 & 5.5 & 0.9 \\
November 2001 & June 2004 & & 5.6 & 5.2 & 0.4 \\
June 2009 & $?$ & $?$ & $5.4^{*}$ & $?$
\end{tabular}

NOTE: *January 2015 CBO estimate for the natural rate of unemployment for 2015 (5.4 percent).

Figure 7 plots the unemployment rate together with estimates of the natural rate of unemployment $\left(u^{*}\right)$ as published by the Congressional Budget Office (CBO). The $\mathrm{CBO}$ estimates are shown because of the availability of a long and consistent history of estimates, which are revised about once a year. The time-series estimate published in January 2015 is shown in blue. Comparison with the unemployment rate time series can give us an indication of the timing of liftoff relative to the most recent estimates of what the natural rate of unemployment was at the time. Since these estimates are revised, however, a more informative comparison for policy- 


\section{Orphanides}

making would be with estimates of the natural rate available in real time. The real-time CBO estimates are shown in red. ${ }^{8}$

Figure 7 illustrates that, after past recessions, policy liftoff occurred well ahead of the unemployment rate reaching estimates of the natural rate of unemployment. This holds both when the January 2015 as well as real-time estimates of the natural rate are used. As shown in Table 2, in the 2004 and 1994 episodes, liftoff occurred while the unemployment rate was almost half a percentage point and almost 1 percentage point, respectively, above the estimates of the natural rate of unemployment the CBO had published at that time. In 1983, the gap exceeded 4 percentage points, consistent with the tight policy bias needed to restore price stability.

In contrast, the current episode points to a case of the missing liftoff. The latest available observation for the unemployment rate (for April 2015) coincides with the January 2015 CBO estimate of the natural rate; and, given the additional decline in the unemployment rate expected over the coming months, it appears that liftoff will not have occurred until after the unemployment rate falls below this estimate of the natural rate.

Fear of liftoff represents a significant aberration relative to the successful conduct of monetary policy in recent decades. To understand the adverse consequences of a delay in normalizing policy one needs only to return to the basic principles of policy design. In light of the long and variable transmission lags, monetary policy ought to be preemptive. If policymakers wish to ensure full employment and price stability over time, they cannot afford to permit immense policy accommodation in the system once full employment is reached. If they did, it would not be feasible to withdraw that accommodation on time without either generating inflation or tightening so abruptly it could cause a recession. For this reason, policy normalization ought to commence long before reasonable estimates suggest full employment has been restored.

The Federal Reserve followed this prudent, preemptive approach after every recession in recent decades. This strategy kept inflation in line with reasonable price stability and avoided stop-go cycles and abrupt and costly corrections. Not this time. Six years after the end of the Great Recession, the Federal Reserve has yet to begin the process of normalization from the unprecedented monetary accommodation it engineered during and after the Great Recession.

The apparent delay in liftoff would be less severe than suggested above if the correct measure of full employment corresponds to a natural rate of unemployment that is significantly below the January 2015 CBO estimate. Indeed, we cannot know what the appropriate threshold is. Estimates of the natural rate are highly uncertain and subject to revision. Table 3 presents a list of alternative suggested estimates that have been published recently (on the dates shown). The January 2015 CBO estimate falls within the range of alternative estimates, including those based on responses to survey questions of professional forecasters. The FOMC is also providing indirect readings of participants' views in the Summary of Economic Projections (SEP) that has been published once per quarter in recent years. Specifically, the Committee publishes the range and central tendency of participants' assessments of the unemployment rate expected to prevail in the "longer run." Interestingly, while in December 2014 the central tendency of the implied estimates (5.2-5.5 percent) encompassed the latest reading of the unemployment rate (5.4 percent for April), the most recent central tendency (5.0-5.2 percent) falls somewhat 


\section{Table 3}

\section{Estimates of the Natural Rate of Unemployment}

\begin{tabular}{lcc} 
Source & Date & Estimate (\%) \\
\hline SPF median & August 2014 & 5.5 \\
Blue Chip mean & October 2014 & 5.4 \\
FOMC central tendency & December 2014 & $5.2-5.5$ \\
FOMC range & December 2014 & $5.0-5.8$ \\
CBO & January 2015 & 5.4 \\
Blue Chip mean & March 2015 & 5.1 \\
FOMC central tendency & March 2015 & $5.0-5.2$ \\
FOMC range & March 2015 & $4.9-5.8$
\end{tabular}

below. The range of estimates, which includes all responses, has been notably wider, indicating substantial diversity of views. It changed only slightly from 5.0-5.8 percent in December to 4.9-5.8 percent in March. ${ }^{9}$ For the majority of the Committee, the recent revision could be used to argue that the FOMC's delay in liftoff is not necessarily internally inconsistent with appropriately preemptive policy. But for some members, the unemployment rate has already fallen below the suggested estimate of the natural rate. Overall, the unemployment rate has fallen so much since the end of the recession, relative to most estimates of the natural rate, that liftoff appears to be overdue, judging from the experience of the three earlier recessions.

\section{CAUSES OF FEAR OF LIFTOFF}

What explains fear of liftoff? For an answer, it is useful to go back to the basics and recall the mandate of the Federal Reserve and how policy decisions are made.

One problem is the muddled mandate of the Federal Reserve. More precisely, the wording of the mandate is open to interpretations that can potentially create immense problems for policymaking:

The Board of Governors of the Federal Reserve System and the Federal Open Market Committee shall maintain long run growth of the monetary and credit aggregates commensurate with the economy's long run potential to increase production, so as to promote effectively the goals of maximum employment, stable prices, and moderate long-term interest rates. (Federal Reserve Act, Section 2A, 1977 amendment; U.S. Congress, 1977)

In the last sentence, the goals of "maximum employment" and "stable prices" suggest an incoherent mandate. How can the Federal Reserve simultaneously achieve maximum employment and stable prices? Through more accommodative monetary policy, one can always get more employment today if one is willing to risk unstable prices later on. While the Federal Reserve is an independent central bank, which facilitates setting policy in accordance with a clear mandate, it has a muddled mandate that creates ambiguity about what it should be aiming for. 


\section{Orphanides}

The muddled mandate invites potentially harmful discretion. It need not cause great harm when the mandate is interpreted in the proper manner, but it can create notable difficulties when it is not.

What creates the risk of bad outcomes? A key issue is the real-time uncertainty and disagreement regarding what constitutes "maximum employment" and its incompatibility with "stable prices." The temptation to explore the limits of the meaning of maximum employment invites harmful discretion. Discretion could then lead to a short-term focus on what is perceived to be the most salient problem facing policymakers at the time rather than the longterm focus needed to defend social welfare over time. This short-term focus may change depending on economic conditions and circumstances, making policy less systematic over time. Following a painful recession, such as the recent experience, the most salient problem becomes high unemployment. This induces excessive focus on reducing unemployment, creating fear of liftoff after recessions and eventually generating stop-go cycles.

How can we ensure that the policy process within which policymakers operate in practice delivers the best possible decisions? A robust policy framework should account for the difficulties introduced by the Federal Reserve's flawed mandate and address the potential for harmful discretion.

Even with best intentions, policymakers are human and subject to the same sources of biases all humans face. In the presence of biases, proper rules and guidance are needed to make policy decisions that systematically deliver good outcomes over time. Can discretionary policy achieve the "optimal" performance corresponding to an infinite-horizon optimization problem under uncertainty, accurately reflecting social welfare, as is often assumed in theoretical treatments of the monetary policy problem? I do not believe so. Humans are not wired to make decisions in this manner. To explore the implications of this difficulty, we could benefit from a brief look at alternative perspectives, such as a public choice or a cognitive psychology perspective to the policy problem.

\section{THE PUBLIC CHOICE PERSPECTIVE}

The public choice perspective acknowledges the presence of a principal-agent relationship between society and appointed policymakers. Personal objectives of appointed policymakers may not coincide with social objectives. In the context of monetary policy, a question that arises is this: What institutional framework can ensure that policymakers' incentives induce decisions consistent with delivering good outcomes from society's perspective? The problem is well known but traditional treatments of the monetary policy problem tend to ignore this complication. Its relevance can be illustrated by referring to a comment by Milton Friedman on the well-known survey by Stanley Fischer (1990) on "Rules versus Discretion in Monetary Policy." In his survey, Fischer discussed the problems associated with discretionary monetary policy and the advantages of well-designed policy rules in solving the problem of dynamic inconsistency but maintained, as an assumption, the idea that policymakers aimed to achieve price stability and full employment. This prompted the following comment by Friedman, which Fischer reproduced in footnote 52 in the concluding section of his paper: 
The major comment is the omission of what I have increasingly come to regard as Hamlet on this issue [rules versus discretion], namely the public choice perspective. To illustrate... you talk about a loss function for "the policymaker" that includes solely inflation and the deviation of real output from a target level. If we bring this down to earth, these are likely to be only very indirectly related to the real objectives of the actual policymakers. From revealed preference, I suspect that by far and away the two most important variables in their loss function are avoiding accountability on the one hand and achieving public prestige on the other. A loss function that contains those two elements as its main argument will I believe come far closer to rationalizing the behavior of the Federal Reserve over the past 73 years than one such as you have used. (Quoted in Fischer, 1990, p. 1181)

To be sure, Friedman's claim that "avoiding accountability" and "achieving public prestige" may be a more accurate description of the personal goals of actual policymakers than the economic objectives typically associated with central bank mandates may appear extreme. Indeed, judging from my personal observation of the global central banking community, I would argue that, overall, in the case of the Federal Reserve, this is not a good characterization. On the other hand, Friedman's description of how actual policymakers operate rings true with a frequency that is not insignificant in other parts of the world, and it cannot be excluded outright as a possible future issue for the Federal Reserve. Success in this regard is sensitive to maintaining an effective appointment process, drawing on tradition, a high degree of professionalism, and the reputation of the institution, something that might be compromised even in an otherwise well-functioning democracy. Around the world, unfortunately, examples of failure are not uncommon.

Needless to say, to the extent Friedman's description holds true, even partially, the monetary policy decisions that would be made by a central bank operating under discretion would be vastly different than those expected by policymakers guided purely by the mandate of the central bank.

The broader issue for policy design is that we are well advised to think outside the realm of traditional macroeconomic policy analysis if we wish to ensure that the institutional framework in place facilitates decisions that are systematic and consistent with good economic outcomes over time. To that end, we should account for the fact that policymakers are human and subject to temptations and biases that would lead to difficulties when they are asked to make decisions with discretion, especially when faced with a muddled mandate, as is the case for the Federal Reserve.

\section{THE COGNITIVE PSYCHOLOGY PERSPECTIVE}

Another source of biases that make discretion potentially harmful draws on cognitive psychology. The problem can be briefly illustrated by referring to George Akerlof's 1990 Ely Lecture on "Procrastination and Obedience."

The relation to the monetary policy problem becomes obvious when the intertemporal trade-off that defines procrastination is considered. According to Akerlof (1991, p. 1):

Procrastination occurs when present costs are unduly salient in comparison with future costs, leading individuals to postpone tasks until tomorrow without foreseeing that when tomorrow comes, the required action will be delayed yet again. 
The description of the problem exactly reflects the intertemporal challenge embedded in the monetary policy problem when considering the trade-off between unemployment and inflation. At the margin, monetary policy can always reduce the present cost of high unemployment by easing policy further. On the other hand, overdoing this and pushing down the unemployment rate too hard only generates a future cost. This is the cost associated with rising inflation, which would be expected to materialize with a long lag.

Fear of liftoff can be seen as the manifestation of procrastination in monetary policy. Procrastination describes a behavioral pathology that would appear inconsistent with decisions that properly account for the future cost of today's decisions for action or inaction. This is a pathology that may hamper not only individuals in their private lives but also policymakers. And it is a pathology that may be very difficult to detect when policymakers operate under discretion. In the presence of uncertainty, it may be virtually impossible for an outside observer to distinguish when a discretionary decision represents a deviation from good practice, the result of a behavioral pathology, and when it reflects sound judgment, efficiently incorporating information the policymaker may possess that may not be available to the outside observer. Even when the outlook for the economy would ordinarily call for policy action, an asymmetry of perceived risks may be invoked during a recovery to justify the discretionary decision to delay normalization.

As Akerlof (1991, p. 2) notes, cognitive psychology can help us understand one source of this pathology:

A central principle of modern cognitive psychology is that individuals attach too much weight to salient or vivid events and too little weight to nonsalient events.

Since the Great Recession, the public policy debate has become greatly influenced by the fear of high unemployment. In the current context, the cognitive psychology perspective would identity unemployment as the salient element driving policy decisions, thus explaining fear of liftoff.

\section{A LEGACY OF THE GREAT RECESSION}

The inconsistency of the goals of maximum employment and price stability in the Federal Reserve's mandate becomes problematic when the mandate is interpreted in a manner that directly or indirectly places excessive emphasis on maximum employment. Monetary policy acquires an activist bent, familiar from the experience of the 1960s and 1970s. By pushing too hard to lower unemployment when it is perceived to be high, policy sets in motion a stop-go cycle dynamic that ultimately hinders macroeconomic performance.

One way to avoid this problem is by clarifying the Federal Reserve's mandate with legislative action. ${ }^{10}$ Another way is for the Federal Reserve to adopt on its own an alternative interpretation of its mandate, one that views price stability as a primary operational objective, based on the rationale that doing so provides the best way to ensure maximum sustainable growth and employment over time. Indeed, this is the interpretation of the mandate that prevailed throughout the Great Moderation era. For a generation that spanned the Fed chairmanships 
of Paul Volcker and Alan Greenspan, price stability was seen as a precondition for achieving maximum sustainable employment over the long run and that served to protect against the short-sighted bias that overemphasizes short-term gains in employment.

This was possible precisely because of the traumatic experience associated with the Great Inflation. ${ }^{11}$ For a generation, high inflation had become the most salient cost in the monetary policy debate, facilitating an interpretation of the Federal Reserve's mandate that appropriately focused on protecting the economy against that malaise over the long run.

This changed during the Great Recession. Without the experience of high inflation in recent memory to serve as a shield, unemployment costs became unduly salient. In essence, the experience of the Great Recession changed the relative weights placed on the incompatible goals of maximum employment and price stability. Unsatisfied with a slow pace of recovery, the Federal Reserve moved toward a more literal interpretation of its mandate, elevating the aversion to temporarily high unemployment and reverting to destabilizing discretion.

On January 25, 2012, the FOMC formalized this shift with the publication of a statement on its long-run objectives and strategy that reiterated its new position:

The Federal Open Market Committee (FOMC) is firmly committed to fulfilling its statutory mandate from the Congress of promoting maximum employment, stable prices, and moderate long-term interest rates. (Board of Governors of the Federal Reserve System, 2012)

In December 2012, three and a half years after the end of the recession, the FOMC even took the unprecedented step of adopting a numerical threshold for the unemployment rate as a formal guide for injecting additional policy accommodation into the economy through QE.

A legacy of the Great Recession has been a shift to a policy framework that places greater emphasis on the goal of maximum employment than had been the case during the Great Moderation era. In this environment, discretionary policy once again risks setting in motion the adverse stop-go policy dynamic experienced in the period before the Great Moderation.

To be sure, it could be suggested that bringing the notion of maximum employment to the forefront as an operational goal for the Federal Reserve is entirely appropriate in the interest of clarity and transparency, given the Federal Reserve's statutory mandate. Indeed, in its statement on long-run objectives, the Committee argued that such clarity enhances transparency and accountability, which are essential in a democratic society. However, the real issue is not to acknowledge the long-run objectives of the Federal Reserve, but rather to adopt an operational framework that ensures that policy can contribute in the best possible manner toward the attainment of these objectives, accounting for the behavioral biases that human nature introduces in the policy process.

\section{THE CASE FOR POLICY RULES}

How can systematic monetary policy that robustly contributes to social welfare be best ensured over time? By the end of the twentieth century, vast historical experience had been accumulated on what constitutes best practice in central banking. The adverse consequences of political interference and behavioral biases that give rise to the dynamic inconsistency prob- 


\section{Orphanides}

lem-and more broadly the limits of monetary policy—-were better recognized. Attitudes shifted away from excessive policy activism, especially after the Great Inflation, giving rise to a rebirth of modern central banking organized on two pillars: an independent central bank with a clear primary mandate to preserve price stability. In numerous economies, this was codified in the law. For example, in the case of the European Central Bank, the 1992 Maastricht Treaty explicitly recognizes that " $\mathrm{t}]$ he primary objective...shall be to maintain price stability."

In the United States, given the Federal Reserve's current mandate, its independence is insufficient to ensure systematic policy over time. Even with the best intentions, central bank independence is not enough to protect against human nature, harmful discretion, and political pressure. The question remains how to help the appointed policymakers contribute in a robust manner, accounting for the practical limitations and biases induced by the current institutional environment and human nature.

The answer is policy rules. The central bank should eschew discretion in favor of a transparent, easy-to-monitor strategy—a policy rule. The central bank should heed warnings known for millennia already and follow the discipline demonstrated by Odysseus to overcome the temptation of harmful discretion. The adoption of a policy rule can ensure a proper long-term policy focus, solve dynamic inconsistency problems, and circumvent behavioral biases that hamper policymaking in practice.

The key remaining question should be how to select the rule that should replace the meeting-by-meeting reliance on discretion. The focus should be on the process for designing, evaluating, and implementing a simple and robust policy rule. As is well understood, simple policy rules have strengths and weaknesses relative to optimal, adaptable, rationally designed plans. But theoretical benchmarks of optimality are always based on models with simplifying assumptions that are known not to hold exactly in reality. Acknowledgment of the "suboptimality" of any simple rule relative to an unattainable theoretical benchmark cannot be used as an excuse for defending discretion.

A large body of accumulated research offers guidance on how to evaluate alternative simple rules and assess their robustness in light of the pervasive uncertainties and complexity of the economy. ${ }^{12}$ Alternative specifications suggest simple formulas that can preserve price stability over time while being somewhat countercyclical with respect to output and employment. Examples include specifications based on the classic Taylor rule that set the policy rate to equal the natural rate of interest plus a linear function of inflation and the unemployment gap-the difference between the actual level of unemployment and its natural rate. Known limitations of these rules include our ignorance of the natural rates of either the interest rate or the unemployment rate in real time, when policy decisions are made. Other specifications, building on the insights of Knut Wicksell and Milton Friedman about dealing with unknown natural rates, specify that changes of the policy rate respond to inflation and changes in the unemployment rate. The rules can be based on historical data or on short-term economic projections of inflation and economic activity, providing an extensive menu of options that could be considered and evaluated before the preferred rule to be implemented is adopted. Existing evaluation work, based on estimated models, suggests that simple rules can be robust to a range of pitfalls that hamper theoretical optimal policy benchmarks. 
However, in light of the complexity of the economy, the limitations and continuous evolution of our understanding, and the constant adaptation of empirical models available for policy analysis, no fixed rule could be expected to perform equally well at all times. This suggests that discretionary policy should not be replaced with a fixed and immutable simple rule but rather with a framework for selecting a simple robust rule that foresees periodic reviews and adaptation.

The authority to use discretion to decide policy on a meeting-by-meeting basis by appointed Federal Reserve policymakers could be replaced with the authority to use discretion to select the simple policy rule policymakers see as most appropriate on the basis of the available state of knowledge. Given the rigor and expertise available in the Federal Reserve System, the Federal Reserve is arguably best placed to develop the simple rule that (i) reflects the present state of knowledge (and ignorance) and (ii) is robust to error. At the same time, recognizing the complexity and limited understanding of the economic environment, there is merit to reevaluation of the selected simple policy rule and scope for periodic review and adaptation of the simple rule the central bank would commit to adhere to.

Replacing the meeting-by-meeting discretion with a transparent process of selecting and periodically adapting a simple and robust policy rule would ensure that monetary policy is systematic and robustly contributes to social welfare over time while also retaining the flexibility to account for the evolution of our understanding of the economic environment. To render the policymakers accountable and eliminate meeting-by-meeting discretion, the selected rule should be transparent and specified with sufficient detail that an outside observer is able to determine the meeting-by-meeting setting of policy using only public information and without any additional input from the Federal Reserve. For example, if the rule's implementation required use of unobserved concepts, such as the natural rates of interest $\left(r^{*}\right)$ or unemployment $\left(u^{*}\right)$, the methodology for arriving at the pertinent estimates should also be specified in advance to make the rule meaningful and avoid discretion. ${ }^{13}$ Similarly, if the rule uses short-term projections of inflation or unemployment, these could not be projections produced by the Federal Reserve, thereby incorporating judgment in a discretionary manner.

In principle, publication of a simple rule could be legislated along the lines of legislative proposals that have been discussed in recent years. ${ }^{14}$ However, legislation of any specific rule or procedure is not necessary and considerable scope for improvement is available for the Federal Reserve under the legislation currently in place. Within its mandate, the Federal Reserve can and would be well advised to embrace and implement improvement on its own.

Within its mandate, the Federal Reserve could publish a simple rule along the lines of its publication of the Committee's principles regarding its longer-run goals and monetary policy strategy. Publishing a simple policy rule, together with the methodology used to select it and the necessary information to replicate and monitor it with publicly available data, would be a quantum leap in enhancing transparency and accountability. By committing to a transparent process of adaptation of the simple rule only after periodic reviews to account for changes in the state of knowledge of the economy, the Federal Reserve would solve the current dynamic inconsistency problems and circumvent behavioral biases that hamper policymaking in practice. 


\section{Figure 8}

\section{Measures of Inflation Expectations}

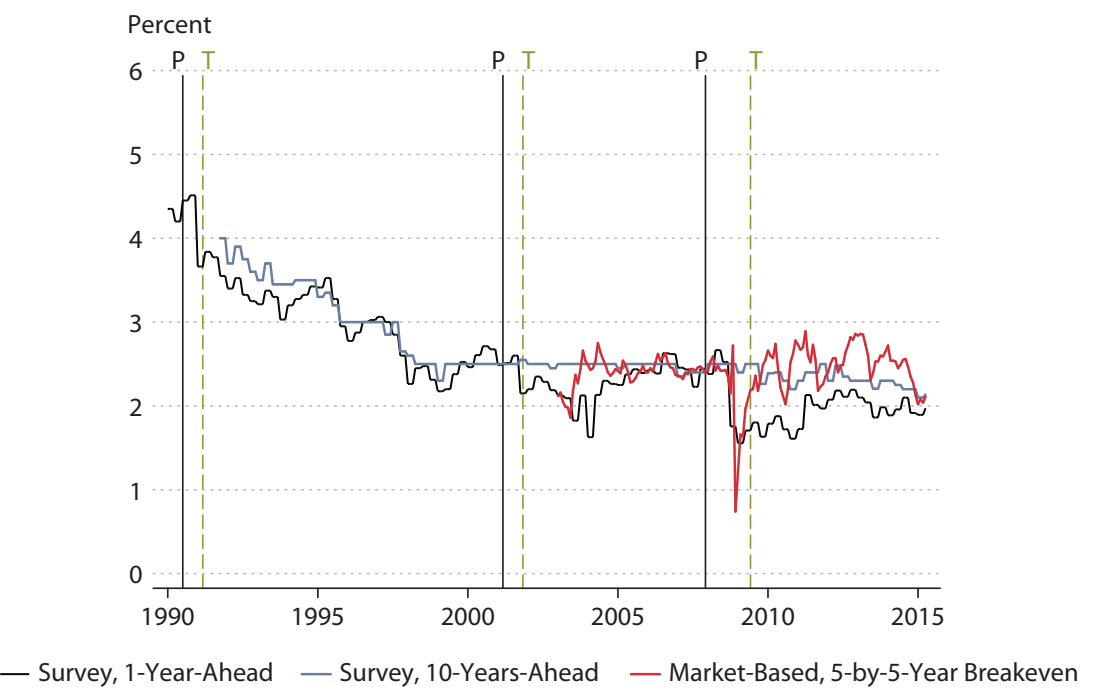

NOTE: The 5-by-5-year breakeven rate is derived using prices on Treasury bonds and Treasury inflation-protected securities. The vertical lines denote business cycle peaks $(P)$ and troughs $(T)$.

SOURCE: FRED ${ }^{\oplus}$, Federal Reserve Economic Data, Federal Reserve Bank of St. Louis for 5-by-5-year breakeven data; Federal Reserve Bank of Philadelphia for survey data.

\section{WHY WORRY NOW?}

The publication of a simple rule by the Federal Reserve would solve the monetary policy quandary created in the current institutional environment by discretion and effectively tackle fear of liftoff. Failing to address the problem would slowly but surely result in policy backsliding to the methods and results experienced before the Great Moderation era.

One might wonder why we should worry now, since discretion has been with us for some time-including during the Great Moderation era. The concern arises once we recognize the role of generational dynamics and learning in the macroeconomy. Despite the massive monetary policy easing engineered during and after the Great Recession, and despite the demonstrated reluctance to embark on policy normalization in line with the experience following recessions during the Great Moderation era, inflation expectations remain well anchored. Pertinent survey- and market-based measures of expectations (Figure 8) suggest no adverse consequences on inflationary psychology.

With inflation currently contained, the risks associated with the Federal Reserve's reinterpretation of its mandate to place greater weight on maximum employment are not immediate. The key question is whether the Federal Reserve could continue to maintain its reputation as a bulwark of price stability, despite the greater emphasis it appears to currently attach to maximum employment, once inflation starts rising with the continuing expansion of the economy. 


\section{Figure 9}

\section{Long-Term Inflation Expectations}

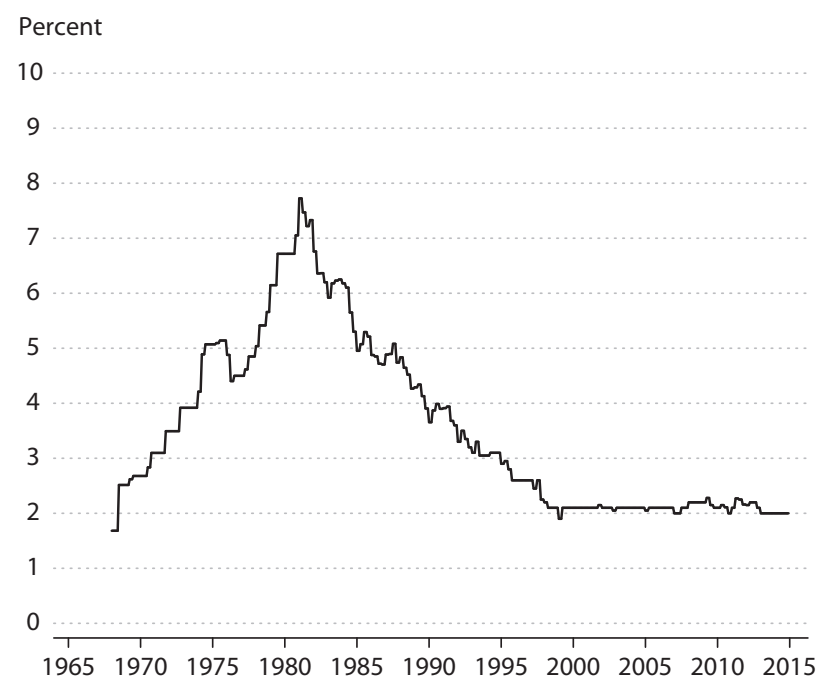

NOTE: Long-term inflation expectations proxy in FRB/US model.

SOURCE: Federal Reserve Board FRB/US model database.

At present, the Federal Reserve continues to benefit from the reputation it slowly acquired over a generation with systematic policy that stressed the primacy of price stability.

However, it would be a grave error to take for granted the stability of inflation expectations currently observed. Reputation is earned and expensed over time. Inflation expectations are well anchored until they are not. In the absence of systematic policy, rising inflation could lead to rapid deterioration of the Federal Reserve's reputation-a significant cost that would tax society in the future and would have to be tackled by future policymakers. The historical evolution of the proxy of long-term inflation expectations used in the Federal Reserve's FRB/US model (Figure 9) can serve as a reminder of this pattern. The figure highlights both the process of unanchoring inflation expectations in the 1960s and 1970s-the penalty of activist policies overemphasizing maximum employment during that period-and the slow improvement that spanned much of the chairmanships of Paul Volcker and Alan Greenspan.

\section{ASYMMETRIC RISKS AND LEARNING}

The long period of unchanged policy rates experienced in recent years may make the delay in embarking on the policy normalization process especially costly in the current context. This is due to the dynamic uncertainty regarding the impact of raising policy rates on inflation and unemployment-the so-called multiplier uncertainty. The effectiveness of a change in policy rates is always uncertain and recent history is always helpful in calibrating it with greater 


\section{Orphanides}

accuracy. The propensity for policy mistakes is smaller when policymakers can be more confident of the effect of the incremental increase in policy rates on inflation one or two years later. With policy rates unchanged near zero since 2008, a significant benefit of an earlier liftoff would be the added information about the effectiveness of the Federal Reserve's normalization strategy. 15

Consider the two possibilities for error following an increase in the policy rates in the current environment. If the tightening were to prove more effective than expected, the implication would be that additional tightening could be introduced at a slower pace. Given the immense policy accommodation currently in the system, the associated cost would be small. On the other hand, if the tightening were to prove less effective than expected, much more tightening and at a faster pace would be needed than anticipated, at a significantly higher associated cost. ${ }^{16}$

Fear of liftoff raises the odds that the Fed will soon be confronted with a costly dilemma: Tighten policy abruptly to control inflation, precipitating a recession? Or let the inflation genie out of the bottle to avoid recession? The greater the delay, the greater the risk that an orderly unwinding of monetary policy accommodation becomes virtually impossible.

\section{MARTIN'S PUNCH BOWL}

Recounting the monetary policy problem faced by the Federal Reserve on an earlier occasion, six decades ago, provides an appropriate end to our historical journey. Liftoff after the recession that ended in May 1954 occurred in April 1955, while the economy was recovering but while employment conditions fell short of what many considered compatible with full employment at that time. ${ }^{17}$ As Chairman William McChesney Martin Jr. (1955) explained later that year, the Federal Reserve did not expect to be applauded for restricting credit to protect against the threat of future inflation:

In the field of monetary and credit policy, precautionary action to prevent inflationary excesses is bound to have some onerous effects-if it did not it would be ineffective and futile. Those who have the task of making such policy don't expect you to applaud. The Federal Reserve, as one writer put it, after the recent increase in the discount rate, is in the position of the chaperone who has ordered the punch bowl removed just when the party was really warming up.

Discretionary decisions bound to have some onerous effects in the present will always face hesitation and resistance when the anticipated benefits are more uncertain and in the distant future. Liftoff is the monetary policy equivalent of removing the punch bowl from the party.

The basic question has not changed in the 60 years since those remarks: How can we ensure that the Federal Reserve will consistently act in a systematic, forward-looking manner promoting stability and prosperity over time? Monetary policymaking can become more robust, drawing on lessons from expanded horizons outside the realm of traditional economic analysis about the challenges and limitations posed by the institutional environment and human nature. Discretionary policy should be eschewed to ensure systematic policy. However, meeting-by- 
meeting discretion need not be replaced with a fixed and immutable simple rule, since any simple rule would require some adjustment over time, but rather with a framework for selecting a simple robust rule that foresees periodic reviews and adaptation.

Legislation could help Federal Reserve policymakers by providing a clearer mandate and guidelines toward the adoption of a policy rule. But legislation would not be needed if the Federal Reserve embraces improvements that can be implemented under current law. Within its mandate, the Federal Reserve could publish a simple rule along the lines of the publication of its longer-run goals, together with information needed to replicate and monitor it. In this manner, the Federal Reserve would eschew meeting-by-meeting discretion. The Federal Reserve would retain the discretionary authority for periodic review and adaptation of its rule, using the expertise available in the Federal Reserve System. This would be a quantum leap in enhancing transparency and accountability toward securing the Federal Reserve's contribution to long-lasting stability and prosperity in the nation. 


\section{Orphanides}

\section{NOTES}

1 Williamson (2015) reviews challenges posed by the normalization question. In remarks at the March 20, 2015, meeting of the Shadow Open Market Committee, John Taylor characterized this concern as monetary policy having entered a "strategy-free zone" (Taylor, 2015). Recent examples of calls to change the legal framework of the Federal Reserve include the Federal Reserve Accountability and Transparency Act of 2014 and the Financial Regulatory Improvement Act of 2015 (U.S. Congress, 2014, 2015).

2 Such questions have been part of the extensive "rules vs. discretion" debate over several decades. See Fischer (1990) for an early survey, Tavlas (2015) for a recent historical treatment, and McCallum (2004) and Goodfriend (2014) for discussions focused on the Federal Reserve.

3 Bernanke (2004) offers a concise review of the likely causes of the Great Moderation. The historical analysis of the Federal Reserve presented by Hetzel (2008), Meltzer (2009), and Lindsey (forthcoming) offers more extensive discussions of the evolution of the Federal Reserve's monetary policy framework.

4 Unless otherwise stated, the point of reference is the date the lecture was delivered (June 3, 2015). The latest data available at that time were used.

5 Expressing this additional easing in numerical terms comparable to conventional reductions in policy rates is not immediate, but estimates suggest that the additional accommodation engineered by the Federal Reserve with unconventional policy could be equivalent to a few hundred basis points of conventional policy easing (D'Amico et al., 2012, and Engen, Laubach, and Reifschneider, 2015).

6 See, e.g., Orphanides (2003) and Orphanides and Williams (2005).

7 Chair Yellen's remarks on normalizing monetary policy offer a recent example (Yellen, 2015).

8 The estimate shown for 2004, for example, is the one published in 2004, which is somewhat higher than the estimate for 2004 published in January 2015.

9 The central tendency excludes the three highest and three lowest projections provided.

10 See, e.g., Orphanides (2014).

${ }^{11}$ Lindsey, Orphanides, and Rasche (2005) document the considerations behind Volcker's reform in October 1979.

12 Taylor and Williams (2010) present a comprehensive survey. In recent years, the development of model databases, such as that of Wieland et al. (2012), has greatly simplified examining robustness properties of alternative simple rules across large numbers of estimates models. See Orphanides and Wieland (2013) for a recent application. Using the Federal Reserve's FRB/US model, Tetlow (2015) demonstrates the critical nature of tracking the robustness of alternative rules even across alternative vintages of the same model.

13 The example provided in footnotes 4 and 5 in Yellen (2015) usefully illustrates the need for sufficient detail. Yellen compared actual policy with the prescription that could be obtained from a Taylor rule whose implementation requires use of specific values for both $r^{*}$ and $u^{*}$. The form of the rule Yellen selected was $f=r^{*}+\pi+0.5(\pi-2)+$ $1.0\left(u-u^{*}\right)$, where $f$ denotes the federal funds rate, $\pi$ the rate of inflation using a core consumer price index, and $u$ the unemployment rate. Yellen noted that this rule was consistent with actual policy at the time of the speech if the values $r^{*}=0$ and $u^{*}=5.0$ were chosen. With the Taylor rule, if assumptions regarding the natural rates could be chosen in a discretionary fashion, any discretionary decision could be described as consistent with the rule.

14 See, e.g., the Federal Reserve Accountability and Transparency Act of 2014 (U.S. Congress, 2014).

15 Since the Federal Reserve has suggested that it intends to rely on increases in policy rates to unwind the accommodation not only due to reductions in interest rates but also due to the expansion of the Federal Reserve's balance sheet, the multiplier uncertainty on policy rates is of even greater importance.

${ }^{16}$ This is an example of asymmetries in learning and the value experimentation under uncertainty (Wieland, 2000).

${ }^{17}$ The discount rate was raised from 11/2 to 13/4 percent on April 13, 1955. The unemployment rate registered 5.0 percent in March 1955, while 4 percent was widely viewed as the rate corresponding to full employment at the time. 


\section{REFERENCES}

Akerlof, George ."Procrastination and Obedience." American Economic Review, May 1991, 81(2), pp. 1-19.

Bernanke, Ben S. "The Great Moderation." Presented at the meetings of the Eastern Economic Association, Washington, DC, February 20, 2004; http://www.federalreserve.gov/BOARDDOCS/speechES/2004/20040220/.

Bernanke, Ben S. "Monetary Policy Since the Onset of the Crisis." Presented the Federal Reserve Bank of Kansas City Economic Policy Symposium The Changing Policy Landscape, Jackson Hole, WY, August 31, 2012; https://www.kansascityfed.org/publicat/sympos/2012/Bernanke_final.pdf.

Board of Governors of the Federal Reserve System. "Statement on Longer-Run Goals and Monetary Policy Strategy." "Press Release." January 25, 2012; http://www.federalreserve.gov/newsevents/press/monetary/20120125c.htm.

D’Amico, Stefania; English, William; Lopez-Salido, David and Nelson, Edward. "The Federal Reserve's Large-Scale Asset Purchase Programs: Rationale and Effects." Economic Journal, October 2012, 122(564), pp. F415-46.

Engen, Eric; Laubach, Thomas and Reifschneider, David. "The Macroeconomic Effects of the Federal Reserve's Unconventional Monetary Policies." Finance and Economic Discussion Series Working Paper 2015-005, Federal Reserve Board, January, 2015; http://www.federalreserve.gov/econresdata/feds/2015/files/2015005pap.pdf.

Fischer, Stanley. "Rules versus Discretion in Monetary Policy," in Benjamin M. Friedman and Frank H. Hahn, eds., Handbook of Monetary Economics, Volume II. Chap. 21. Amsterdam: Elsevier, 1990, pp. 1155-84.

Goodfriend, Marvin. "Lessons from a Century of FED Policy: Why Monetary and Credit Policies Need Rules and Boundaries." Journal of Economic Dynamics and Control, December 2014, 49, pp. 112-20.

Hetzel, Robert. The Monetary Policy of the Federal Reserve: A History. New York: Cambridge University, 2008.

Lindsey, David E. A Century of Monetary Policy at the Fed: Ben Bernanke, Janet Yellen, and the Financial Crisis of 2008. London: Palgrave Macmillan, 2016 (forthcoming).

Lindsey, David E.; Orphanides Athanasios and Rasche, Robert. "The Reform of October 1979: How It Happened and Why." Federal Reserve Bank of St. Louis Review, March/April 2005, 87(2 Part 2), pp. 187-235;

https://research.stlouisfed.org/publications/review/05/03/part2/MarchApril2005Part2.pdf.

McCallum, Bennett. "Misconceptions Regarding Rules vs. Discretion for Monetary Policy." Cato Journal, Winter 2004, 23(3), pp. 365-72; http://object.cato.org/sites/cato.org/files/serials/files/cato-journal/2004/1/cj23n3-5.pdf.

Martin, William M. Jr. "Address before the New York Group of the Investment Bankers Association of America." New York, October 19, 1955; http://www.federalreservehistory.org/Media/Material/People/113-140.

Meltzer, Allan. A History of the Federal Reserve. Volume 2. Chicago: University of Chicago Press, 2009.

Orphanides, Athanasios. "The Quest for Prosperity without Inflation." Journal of Monetary Economics, April 2003, 50(3), pp. 633-63.

Orphanides, Athanasios. "The Need for a Price Stability Mandate." Cato Journal, Spring/Summer 2014, 34(2); http://object.cato.org/sites/cato.org/files/serials/files/cato-journal/2014/5/cato-journal-v34n2-4.pdf.

Orphanides, Athanasios and Wieland, Volker. "Complexity and Monetary Policy." International Journal of Central Banking, January 2013, 9(1), pp. 167-203; http://www.ijcb.org/journal/ijcb13q0a8.pdf.

Orphanides, Athanasios and Williams, John C. "The Decline of Activist Stabilization Policy: Natural Rate Misperceptions, Learning, and Expectations." Journal of Economic Dynamics and Control, 2005, 29(11), pp. 1927-50.

Tavlas, George. "In Old Chicago: Simons, Friedman, and the Development of Monetary-Policy Rules." Journal of Money, Credit, and Banking, February 2015, 47(1), pp. 99-121;

http://onlinelibrary.wiley.com/doi/10.1111/jmcb.12170/abstract.

Taylor, John. "Getting Back to a Rules-Based Monetary Strategy." Presented at the conference "Getting Monetary Policy Back on Track," presented by the Shadow Open Market Committee, Princeton Club, New York, March 20, 2015; http://web.stanford.edu/ johntayl/2015_pdfs/SOMC-talk\%20_Taylor-3-20-15.pdf.

Taylor, John, and John C. Williams. "Simple and Robust Rules for Monetary Policy," in Benjamin M. Friedman and Michael Woodford, eds., Handbook of Monetary Economics. Volume 3. Chap. 15. Amsterdam: Elsevier, 2010, pp. 825-59. 


\section{Orphanides}

Tetlow, Robert. "Real-Time Model Uncertainty in the United States: 'Robust' Policies Put to the Test." International Journal of Central Banking, March 2015, 11(1), pp. 113-55; http://www.ijcb.org/journal/ijcb15q2a4.pdf.

U.S. Congress. "Amendments to the Federal Reserve Act." Public Law 95-188, November 16, 1977; http://www.gpo.gov/fdsys/pkg/STATUTE-91/pdf/STATUTE-91-Pg1387.pdf.

U.S. Congress. "Federal Reserve Accountability and Transparency Act of 2014." H.R. 5018, July 30, 2014; https://www.congress.gov/bill/113th-congress/house-bill/5018.

U.S. Congress. "The Financial Regulatory Improvement Act of 2015." http://www.banking.senate.gov/public/index.cfm?FuseAction=Files.View\&FileStore_id=8d9a5138-10a3-4a53a48f-86ce373aa880.

Wieland, Volker. "Learning by Doing and the Value of Optimal Experimentation." Journal of Economic Dynamics and Control, April 2000, 24(4), pp. 501-34.

Wieland, Volker; Cwik, Tobias; Mueller, Gernot J.; Schmidt, Sebastian and Wolters, Maik. "A New Comparative Approach to Macroeconomic Modeling and Policy Analysis." Journal of Economic Behavior and Organization, August 2012, 83(3), pp. 523-41.

Williamson, Stephen. "Monetary Policy Normalization in the United States." Federal Reserve Bank of St. Louis Review, Second Quarter 2015, 97(2), pp. 87-108; https://research.stlouisfed.org/publications/review/2015/q2/Williamson.pdf.

Yellen, Janet. "Normalizing Monetary Policy: Prospects and Perspectives." Presented at the Federal Reserve Bank of San Francisco, San Francisco, CA, March 27, 2015;

http://www.federalreserve.gov/newsevents/speech/yellen20150327a.htm. 